\title{
Influence of air-particle deposition protocols on the surface topography and adhesion of resin cement to zirconia
}

\author{
Sarmento, Hugo R ; Campos, Fernanda ; Sousa, Rafael S ; Machado, Joao P B ; Souza, Rodrigo O A ; Bottino,
} Marco A ; Özcan, Mutlu

\begin{abstract}
OBJECTIVES This study evaluated the influence of air-particle abrasion protocols on the surface roughness (SR) of zirconia and the shear bond strength (SBS) of dual-polymerized resin cement to this ceramic. MATERIALS AND METHODS Sintered zirconia blocks $(\mathrm{n}=115)$ (Lava, 3M ESPE) were embedded in acrylic resin and polished. The specimens were divided according to the 'particle type' (Al: $110 \mu \mathrm{m} \mathrm{Al2O}$; Si: $110 \mu \mathrm{m} \mathrm{SiO} 2$ ) and 'pressure' factors (2.5 or 3.5 bar) ( $\mathrm{n}=3$ per group): (a) Control (no air-abrasion); (b) Al2.5; (c) Si2.5; (d) Al3.5; (e) Si3.5. SR (Ra) was measured 3-times from each specimen after $20 \mathrm{~s}$ of air-abrasion (distance: $10 \mathrm{~mm}$ ) using a digital optical profilometer. Surface topography was evaluated under SEM analyses. For the SBS test, 'particle type', 'pressure' and 'thermocycling' (TC) factors were considered ( $\mathrm{n}=10 ; \mathrm{n}=10$ per group): Control (no air-abrasion); Al2.5; Si2.5; Al3.5; Si3.5; ControlTC; Al2.5TC; Si2.5TC; Al3.5TC; Si3.5TC. After silane application, resin cement (Panavia F2.0) was bonded and polymerized. Specimens were thermocycled $\left(6.000\right.$ cycles, $\left.5-55^{\circ} \mathrm{C}\right)$ and subjected to SBS (1 mm/min). Data were analyzed using ANOVA, Tukey's and Dunnett tests (5\%). RESULTS 'Particle' $(\mathrm{p}=0.0001)$ and 'pressure' $(\mathrm{p}=0.0001)$ factors significantly affected the SR. All protocols significantly increased the SR (Al2.5: $0.45 \pm$ 0.02; Si2.5: $0.39 \pm 0.01$; Al3.5: $0.80 \pm 0.01$; Si3.5: $0.64 \pm 0.01 \mu \mathrm{m}$ ) compared to the control group $(0.16 \pm 0.01 \mu \mathrm{m})$. For SBS, only 'particle' factor significantly affected the results $(\mathrm{p}=0.015)$. The $\mathrm{SiO} 2$ groups presented significantly higher SBS results than Al2O3 (Al2.5: $4.78 \pm 1.86$; Si2.5: $7.17 \pm 2.62$; $\mathrm{Al} 3.5: 4.97 \pm 3.74$; $\mathrm{Si} 3.5$ : $9.14 \pm 4.09 \mathrm{MPa})$ and the control group $(3.67 \pm 3.0 \mathrm{MPa})$. All TC specimens presented spontaneous debondings. SEM analysis showed that $\mathrm{Al} 2 \mathrm{O} 3$ created damage in zirconia in the form of grooves, different from those observed with $\mathrm{SiO} 2$ groups. CONCLUSIONS Air-abrasion with $110 \mu \mathrm{m} \mathrm{Al} 2 \mathrm{O} 3$ resulted in higher roughness, but air-abrasion protocols with $\mathrm{SiO} 2$ promoted better adhesion.
\end{abstract}

DOI: https://doi.org/10.3109/00016357.2013.837958

Posted at the Zurich Open Repository and Archive, University of Zurich

ZORA URL: https://doi.org/10.5167/uzh-100705

Journal Article

Accepted Version

Originally published at:

Sarmento, Hugo R; Campos, Fernanda; Sousa, Rafael S; Machado, Joao P B; Souza, Rodrigo O A; Bottino, Marco A; Özcan, Mutlu (2014). Influence of air-particle deposition protocols on the surface topography and adhesion of resin cement to zirconia. Acta Odontologica Scandinavica, 72(5):346-353.

DOI: https://doi.org/10.3109/00016357.2013.837958 
Influence of air-particle deposition protocols on the surface topography and adhesion of resin cement to zirconia

H.R. SARMENTO ${ }^{1}$, F. CAMPOS ${ }^{2}$, R.S. SOUSA ${ }^{3}$, J.P.B. MACHADO ${ }^{4}$, R.O.A. SOUZA ${ }^{5}$, \& M. ÖZCAN ${ }^{6}$

${ }^{1}$ Federal University of Pelotas, Pelotas Dental School, Graduate Program in Dentistry, Pelotas, Brazil, '2São Paulo State University, São José dos Campos Dental School, Department of Dental Materials and Prosthodontics, São José dos Campos, Brazil, ${ }^{3}$ Federal University of Paraíba, João Pessoa, Brazil, ${ }^{4}$ National Institute of Spatial Researches, São José dos Campos, Brazil, ${ }^{5}$ Federal University of Paraíba, Department of Restorative Dentistry, Division of Prosthodontics, João Pessoa, Brazil, and ${ }^{6}$ University of Zürich, Dental Materials Unit, Center for Dental and Oral Medicine, Clinic for Fixed and Removable Prosthodontics and Dental Materials Science, Zürich, Switzerland

Short title: Air-abrasion effect on zirconia topography and adhesion

${ }^{*}$ This study was previously presented at the $28^{\text {th }}$ Annual Meeting of the Brazilian Society of Dental Research (SBPqO), in September $6^{\text {th }} 2011$. 
Correspondance: Mutlu Özcan, University of Zurich, Center for Dental and Oral Medicine, Dental Materials Unit, Clinic for Fixed and Removable Prosthodontics and Dental Materials Science, Plattenstrasse 11, CH 8032, Zurich, Switzerland. E-mail: mutluozcan@hotmail.com 


\section{Abstract}

Objectives. This study evaluated the influence of air-particle abrasion protocols on the surface roughness (SR) of zirconia ceramic and the adhesion of dual-polymerized resin cement to this ceramic. Material and methods. Sintered zirconia blocks $(N=115)$ (Lava, 3M ESPE) were embedded in acrylic resin and polished. The specimens were randomly divided into the following experimental groups considering the particle type (Al: $110 \mu \mathrm{m}$ $\mathrm{Al}_{2} \mathrm{O}_{3}$; $\mathrm{Si}: 110 \mu \mathrm{m} \mathrm{SiO}_{2}$ ) and pressure factors (2.5 or 3.5 bar) (n=3 per group): a) Control (no air-abrasion); b) Al2.5; c) Si2.5; d) Al3.5; e) Si3.5. SR (Ra) was measured 3 times from each specimen after $20 \mathrm{~s}$ of air-abrasion from a distance of $10 \mathrm{~mm}$ using a digital optical profilometer. Surface topography was evaluated under Scanning Electron Microscopy (SEM). For the shear bond strength (SBS) test, "particle type", "pressure", and "thermocycling" (TC) factors were considered $(\mathrm{N}=10 ; \mathrm{n}=10$ per group): Control (no airabrasion); Al2.5; Si2.5; Al3.5; Si3.5; Control $\mathrm{Tc} ; \mathrm{Al2.5}$ Tc; Si2.5Tc; Al3.5Tc; Si3.5Tc. After silane application, resin cement (Panavia F2.0) was bonded and polymerized. Specimens were thermocycled for 6.000 cycles $\left(5-55^{\circ} \mathrm{C}\right)$ and then subjected to SBS $(1 \mathrm{~mm} / \mathrm{min})$. Data were analyzed using ANOVA, Tukey`s and Dunnett tests $(5 \%)$. Results. "Particle" $(p=$ 0.0001) and "pressure" ( $p=0.0001)$ factors significantly affected the SR. All protocols significantly increased the SR (Al2.5: $0.45 \pm 0.02^{\mathrm{C}}$; Si2.5: $0.39 \pm 0.01^{\mathrm{D}} ; \mathrm{Al} .5: 0.80 \pm 0.01^{\mathrm{A}}$; Si3.5: $\left.0.64 \pm 0.01^{B} \mu \mathrm{m}\right)$ compared to the control group $(0.16 \pm 0.01 \mu \mathrm{m})$. For $S B S$, only "particle" factor significantly affected the results $(p=0.015)$. The $\mathrm{SiO}_{2}$ groups presented significantly higher SBS results than $\mathrm{Al}_{2} \mathrm{O}_{3}\left(\mathrm{Al} 2.5: 4.78 \pm 1.86^{\mathrm{B}} ; \mathrm{Si} 2.5: 7.17 \pm 2.62^{\mathrm{A}} ; \mathrm{Al} 3.5\right.$ : 4.97 $\pm 3.74^{\mathrm{B}}$; Si3.5: $\left.9.14 \pm 4.09^{\mathrm{A}} \mathrm{MPa}\right)$ and the control group $\left(3.67 \pm 3^{\mathrm{B}} \mathrm{MPa}\right)$. All TC specimens presented spontaneous debondings. SEM analysis showed that $\mathrm{Al}_{2} \mathrm{O}_{3} \mathrm{created}$ damage in zirconia in the form of grooves, different from those observed with $\mathrm{SiO}_{2}$ groups. 
Conclusions. Air-abrasion with $110 \mu \mathrm{m} \mathrm{Al}_{2} \mathrm{O}_{3}$ resulted in higher roughness but airabrasion protocols with $\mathrm{SiO}_{2}$ promoted better adhesion of the resin cement.

Key Words: adhesion, aluminum oxide, roughness, scanning electron microscopy, shear strength, silicon dioxide, yttria stabilized tetragonal zirconia

\section{Introduction}

Currently, ceramics that are based on zirconium oxide (hereon: zirconia) are being extensively studied because of their more favourable mechanical properties as opposed to other dental ceramics [1]. The polycrystalline tetragonal zirconia partially stabilized with yttria $(\mathrm{Y}-\mathrm{TZP})$ is composed of zirconium dioxide $\left(\mathrm{ZrO}_{2}\right)$ and displays a polymorphic structure that can present different crystalline phases (monoclinic, tetragonal or cubic), depending on the temperature [2]. Yttrium oxide $\left(\mathrm{Y}_{2} \mathrm{O}_{3}\right)$ is one of the most widely used stabilizer for this polycrystalline ceramic. When added (3-6\%) to pure zirconia, it serves to stabilize zirconia at room temperature in the tetragonal phase, resulting in a crystalline material with high mechanical strength [3].

Common clinical failures associated with Y-TZP fixed dental prosthesis (FDP) are chipping of the veneering ceramic [4], framework fracture [4,5], secondary caries [4] and debonding $[4,6]$. The main reason for debonding is poor adhesion between the cement and zirconia $[4,6]$. Hydrofluoric acid etching followed by the application of silane coupling agent in silica-based ceramics is a well-established method to increase the adhesion of resin cement to such ceramics. However, this technique is not effective in zirconia because of its highly stable oxides that makes it resistant to acid etching [7]. Many researchers are engaged in the study of techniques to promote better adhesion between zirconia and resin cement. Several procedures have been suggested for this purpose such as silica deposition by plasma [8], selective infiltration etching [9], use of cements and 
adhesives based on 10-methacryloyloxy-decyl dihydrogenphosphate (MDP) [10], glaze application followed by etching [11] and air-borne particle abrasion [12]. Among all these methods, air-abrasion protocol is a simple, inexpensive technique that can be performed chairside [12]. In an attempt to increase the bond strength of resin cements to zirconia, particles of alumina $\left(\mathrm{Al}_{2} \mathrm{O}_{3}\right)$ and alumina particles coated with silica $\left(\mathrm{SiO}_{2}\right)$ have been used employing different protocols [2,13-16]. Air-abrasion with alumina $[15,17]$ or silica followed by silane application [17] seems to improve adhesion to zirconia. The efficacy of these procedures depends highly on the type of particles. The tribochemical silica coating technique has been shown to be more effective than air-abrasion with ordinary alumina, generating stable adhesion even after water storage for six months [17] or 37.500 thermal cycles for 150 days [14]. Yet, the effect of particle size and pressure during air-abrasion is not clearly known. For this reason, a well-defined pre-treatment protocol for zirconia frameworks is not defined so far [18].

It can be anticipated that the adhesion between resin cement and zirconia would be more durable when micromechanical retention is achieved since a rough ceramic surface would allow the micromechanical interlocking of the resin cement through microretentions [19]. Accordingly, surface roughness of zirconia increases after air-particle abrasion or silica coating [18]. The objective of this study was to evaluate the influence of air-particle abrasion protocols on the surface roughness of zirconia ceramic and the adhesion of dualpolymerized resin cement to this ceramic. The null hypotheses tested were that surface roughness and shear bond strength of the resin cement would not be influenced by the airparticle abrasion protocols applied on zirconia.

\section{Methods and Materials}


The materials used in this study and their respective brands, manufacturers and batch numbers are presented in Table I.

\section{Ceramic block preparation}

Sintered zirconia blocks $(5.25 \mathrm{~mm} \times 5.25 \mathrm{~mm} \times 3 \mathrm{~mm}$ ) (Lava, 3M ESPE, Seefeld, Germany) ( $\mathrm{N}=115)$ were sectioned using a diamond disc (KG Sorensen, Barueri, Brazil) and their surfaces were ground finished with silicon carbide papers of \#600 to \#1200 (3M, St. Paul, USA). The blocks were sintered in a specific furnace (Lava Furnace 200, 3M ESPE) according to the manufacturer's recommendations.

Zirconia blocks were embedded in acrylic resin (Clássico Dental Products Inc., São Paulo, Brazil) using a silicone mold. After polymerization, each resin block was removed from the mold and the zirconia surfaces were ground finished using silicon carbide papers in grit sequence of \#600, \#1200, \#1500 and \#2000 (3M) under water cooling. They were then polished with a diamond paste (Diamond Excel Paste, FGM Dental Products, Joinville, Brazil) with a particle size of $10 \mu \mathrm{m}$ and $3 \mu \mathrm{m}$, followed by colloidal silica (Struers OPS, Struers, Brisbane, Australia), both on felt discs mounted on a polishing machine (Erios, PSK-2V, São Paulo, Brazil).

\section{Air-particle abrasion protocols}

Prior to air abrasion, the blocks were ultrasonically cleaned in $10 \%$ isopropyl alcohol for 5 min (Vitasonic II, Vita Zanhfabrik, Bad Säckingen, Germany). The blocks were placed onto gauze for 10 min to ensure complete alcohol evaporation.

The specimens were randomly divided into the following experimental groups considering the particle type ad pressure (Table II):

Control group: The polished specimens acted as the control group.

Group Al2.5: Zirconia specimens were air-abraded with $110 \mu \mathrm{m}$ aluminium oxide (Polidental Ltd., Sao Paulo, Brasil) at 2.5 bar pressure. 
Group Si2.5: In this group, zirconia specimens were air-abraded with $110 \mu \mathrm{m}$ aluminium oxide coated with silica (Rocatec Plus, 3M ESPE) at 2.5 bar pressure.

In groups Al3.5 and Si3.5 air-abrasion was employed at 3.5 bar pressure.

All air-abrasion protocols were performed using a chairside air-abrasion device (DentoPrep, RØNVIG A/S, Daugaard, Denmark) attached to a metallic device [20], perpendicular to the surface of the ceramic blocks at a distance of $10 \mathrm{~mm}$ for $20 \mathrm{~s}$ with the specified pressure, according to the experimental group. Air-abrasion procedures were performed in circular movements to achieve a uniformly blasted surface.

\section{Surface roughness (SR) analyses}

Based on a previous study [21], the sample size was calculated using $t$ test considering a power of $99 \%$ and $5 \%$ of $\alpha$ error. A sample size of 2 specimens per group was decided but to adjust the sample size due to differences in experimental design, 3 specimens were included in each group.

SR measurement of ceramics ( $N=15, n=3$ per group) after air-abrasion, were analyzed in a digital optical profilometer (Wyko, Model NT 1100, Veeco, USA), which was connected to a computer. The data were analyzed using the specific software (Wyko Vision 32, Wyko, Veeco, USA). Measurements of 3D parameters were performed with $\underline{a}$ magnification of $\times 20$ and an area of $301.3 \times 229.2 \mu \mathrm{m}$. Three measurements were made from each specimen. The roughness values $(\mathrm{Ra})$ were obtained in micrometers.

\section{Surface topography analysis}

Surface topography of the specimens after air-abrasion protocols was analyzed at a magnification of x5000 using Scanning Electron Microscope (SEM, Leo model 1430 VP, Zeiss, Cambridge, UK) equipped with digital software. Prior to gold sputtering, the specimens were cleaned in absolute ethanol ultrasonically (35 kHz) (Vitasonic II) for 10 min. Then the specimens were positioned on a platform of aluminum stub and sputtered 
with a thin conductive layer of gold (50 to 100 Angstron) by vapor deposition in ion sputtering machine (Emitech K550X, Emitech, Ashford Kent, UK).

\section{Specimens for shear bond strength (SBS) test}

For the SBS test, zirconia blocks were randomly divided into 10 groups $(N=100, n=10$ per group), according to the particle type (Al and $\mathrm{Si}$ ), pressure (2.5 and 3.5 bar) and thermocycling (TC, with and without) factors: Control (no air-abrasion); Al2.5; Si2.5; Al3.5; Si3.5; Control $\underline{\underline{T C} ; A l 2.5} \underline{\mathrm{TC}} ; \mathrm{Si} 2.5_{\underline{\mathrm{TC}}} ; \mathrm{Al3.5} \underline{\mathrm{TC}} ; \mathrm{Si3.5} \underline{\mathrm{TC}}$ (Table III).

Silane coupling agent (Clearfil Ceramic Primer, Kuraray, Japan) was applied to the airabraded zirconia surfaces in all groups including the control group with a microbrush (Dentsply, New York, USA) and left to react for $5 \mathrm{~min}$, according to the manufacturer`s recommendations. Then, resin cement (Panavia F2.0, Kuraray) was bonded to the silanized zirconia surfaces with the aid of a silicone mold (diameter: $3.5 \mathrm{~mm}$, height: 3 $\mathrm{mm}$ ). The lower orifice of the silicone mold was positioned in the center of cementation surface of the ceramic, so that the entire layer of cement stayed in contact with the ceramic. With the aid of a plastic spatula, the base paste and catalyst paste were manipulated until homogenization of the cement. The cement was inserted in the silicone mold and photo-polymerized using the incremental technique (3 layers of $1 \mathrm{~mm}$ each). Each layer of cement was photo-polymerized for $40 \mathrm{~s}$ (XL 3000, 3M ESPE; light intensity= $\left.600 \mathrm{~mW} / \mathrm{cm}^{2}\right)$.

\section{Thermocycling}

The specimens from groups Control ${ }_{\mathrm{TC}}, \mathrm{Al} 2.5_{\mathrm{TC}}, \mathrm{Si} 2.5_{\mathrm{TC}}, \mathrm{Al} 3.5_{\mathrm{TC}}$ and $\mathrm{Si} 3.5_{\mathrm{TC}}$ were subjected to thermocycling (TC) (Nova Etica, São Paulo, Brazil) for 6.000 cycles at $5^{\circ} \mathrm{C}$ $55^{\circ} \mathrm{C} \pm 1^{\circ} \mathrm{C}$ in water. The time of immersion in each bath was $30 \mathrm{~s}$ and transfer time between the two baths was $2 \mathrm{~s}$. 
The specimens from groups that were not subjected to TC were stored in distilled water at $37^{\circ} \mathrm{C}$ for $24 \mathrm{~h}$ prior to the SBS test.

\section{Shear bond strength test}

The SBS test was performed in the Universal Testing Machine (EMIC model DL-1000, São José dos Pinhais, Brazil) according to ISO 10477 norm [22]. A metallic device was used to position the specimen in the testing machine so that the ceramic-cement interface was perpendicular to the horizontal plane. A knife-shaped device was placed on the load cell (100 kgf) of the testing machine, and the ceramic-cement interface was loaded at a constant cross-head speed of $1 \mathrm{~mm} / \mathrm{min}$ until debonding.

\section{Failure analysis}

After debonding, failure types were analyzed using a stereomicroscope (Stemi 2000-C, Carl Zeiss, Gottingen, Germany) at x100 magnification.

Failure types were classified as follows: a) adhesive failure between the ceramic-cement;

b) cohesive failure in the ceramic; c) cohesive failure in the cement and d) mixed failure (adhesive failure together with cohesive failure in the cement).

\section{Statistical analyses}

SR data were analyzed using two-way ANOVA (2 levels: particle type and pressure) followed by Dunnett test using a statistical software package (Statistix 8.0 for Windows, Analytical Software Inc, Tallahassee, FL, USA). SBS data were analyzed using three-way ANOVA (3 levels: particle type, pressure and thermocycling) followed by Tukey`s and Dunnett tests $(\alpha=0.05)$.

\section{Results}




\section{Surface roughness}

Both the particle type $(p=0.0001)$ and pressure $(p=0.0001)$ significantly influenced the roughness results (Table IV). Interaction terms were also significant $(p=0.0001)$.

All protocols significantly increased the SR (Al2.5: $0.45 \pm 0.02^{\mathrm{C}}$; Si2.5: $0.39 \pm 0.01^{\mathrm{D}}$; Al3.5: $0.80 \pm 0.01^{\mathrm{A}}$; Si3.5: $\left.0.64 \pm 0.01^{\mathrm{B}} \mu \mathrm{m}\right)$ compared to the control group $(0.16 \pm 0.01 \mu \mathrm{m})$ (Dunett) (Figure 1). The mean SR for the group Al3.5 $\left(0.80 \pm 0.01^{\mathrm{A}} \mu \mathrm{m}\right)$ was significantly higher than those of other groups (Al2.5: $\left.0.45 \pm 0.02^{\mathrm{C}} \mu \mathrm{m}\right)$, Si3.5: $0.64 \pm 0.01^{\mathrm{B}} \mu \mathrm{m}, \mathrm{Si} 2.5$ : $0.39 \pm 0.01^{\mathrm{D}}$ $\mu \mathrm{m})$ (Tukey's test).

\section{Surface topography analysis}

Specimens in Al2.5 and Al3.5 groups presented defects in the form of grooves and chips on their surfaces, indicating that these protocols damage the ceramic surface. Representative photomicrographs of each group and 3D images of these surfaces obtained by digital optical profilometer are presented in Figures 2a-f.

\section{Shear bond strength}

While particle type $(p=0.015)$ significantly affected the SBS results, pressure did not $(p=$ 0.398). Interaction terms were not significant $(p=0.4846)$ (Table V).

Groups Si2.5 $\left(7.17 \pm 2.62^{\mathrm{A}}\right)$ and $\operatorname{Si} 3.5\left(9.14 \pm 4.09^{\mathrm{A}}\right)$ presented the highest SBS values whereas Al2.5 $\left(4.78 \pm 1.86^{\mathrm{B}}\right)$ and Al3.5 $\left(4.97 \pm 3.74^{\mathrm{B}}\right)$ the lowest (Tukey's test) (Figure 3). When the experimental groups were compared to the control group, only groups Si2.5 and Si3.5 promoted significantly higher bond strength $(p<0.05)$.

All groups showed pre-test (PTF) failures during TC (Table VI). Thus, the "thermocycling" factor was not considered in the statistical analysis. 


\section{Failure analysis}

Failure types were predominantly mixed (Score D) in all groups (Table VII). Only in the control group, failure types were exclusively adhesive (Score A). None of the groups showed cohesive failures in the ceramic (Score B).

\section{Discussion}

Based on the results of this study, since particle type and pressure significantly affected the surface roughness of zirconia, and particle type significantly influenced the bond strength of the resin cement, the null hypotheses could be rejected.

The surface roughness values for experimental groups showed statistical differences. The surface analysis by optical profilometry indicated higher roughness values when zirconia surfaces were air-abraded with $110 \mu \mathrm{m} \mathrm{Al}_{2} \mathrm{O}_{3}$ particles under 3.5 bar pressure followed by $110 \mu \mathrm{m}$ alumina particles coated with silica under 3.5 bar. The high precision of optical profilometer being able to detect topographical changes less than $0.1 \mathrm{~nm}$ increases the reliability of the measurements. SEM analysis showed more defects on zirconia surface with the use of $110 \mu \mathrm{m} \mathrm{Al}_{2} \mathrm{O}_{3}$ particles that may be attributed to sharp morphology of the individual particles in this sand type [23]. On the contrary, coating of alumina particles with the silica using sol-gel technologies reduced the sharp morphology of the alumina particles, possibly also reducing the impact of the particles on the zirconia surface. Furthermore, under both 2.5 and 3.5 bar pressure, $\mathrm{Al}_{2} \mathrm{O}_{3}$ generated surface roughness being statistically higher than with $\mathrm{SiO}_{2}$. Although the particle size was similar, namely $110 \mu \mathrm{m}$, this finding indicates that the variation in particle morphology is of importance. These results were similar to those reported in an in vitro investigation where atomic force microscopy was used to detect the surface roughness [24]. Whether surface 
damage created with $110 \mu \mathrm{m} \mathrm{Al}_{2} \mathrm{O}_{3}$ particles is detrimental for clinical success of zirconia FDPs needs to be verified in clinical studies.

In this study, all air-abrasion protocols provided micromechanical retention and thereby better bond strength than the control group, supporting the findings of previous studies $[16,25,26]$. Interestingly however, high surface roughness obtained with $\mathrm{Al}_{2} \mathrm{O}_{3}$ under both 2.5 and 3.5 bar pressure did not necessarily yield to higher bond strength. This implies that chemical aspect of physico-chemical conditioning was more favourable for $\mathrm{SiO}_{2}[10,14,15]$. Although tribochemical conditioning using Rocatec Plus necessitates the use of 3methacryloxypropyltrimethoxysilane (MPS) silane according to the manufacturer, and MDP-based silane was used which is the recommendation of the resin cement tested. Phosphate ester groups in this silane bond directly to the surface oxides of zirconia and the methacrylate group makes covalent bonds with the resin matrix of the cement $[27,28]$. In a previous study, slightly better results were obtained in dry conditions when an MPS silane was used in combination with bis-GMA cement. However, also in that study, after aging conditions, practically no adhesion was achieved [7]. This implies that both MPS and MDP-based silanes do not provide hydrolytically stable interfaces with the resin cement and zirconia.

In this study, air-abrasion protocols were applied for $20 \mathrm{~s}$ based on the results of some preliminary studies. No statistically significant difference on the bond strength between the two different pressures, 2.5 and 3.5 bar, regardless of particle type. This may change when zirconia surfaces are air-abraded for prolonged durations.

An important factor that influences bond strength is the aging in with thermocycling, which is often used in in-vitro studies to simulate the worse-case clinical conditions. There is no consensus on a relevant protocol for artificial aging by thermocycling. In general, average temperatures of $5^{\circ} \mathrm{C}$ and $55^{\circ} \mathrm{C}$ have been used as the lower and upper 
temperature in the water tanks [29]. The ISO 11405 norm indicates that 500 cycles in water at $5^{\circ} \mathrm{C}-55^{\circ} \mathrm{C}$ is an appropriate method for aging resin-tooth interfaces [30]. Moreover, Gale and Darvell [23] reported that 10.000 cycles corresponds to approximately 1 year of in vivo function. In the present study, 6.000 thermocycles with an immersion time of $20 \mathrm{~s}$ in each bath, corresponds to a period of approximately 7.2 months of clinical use.

Previous studies have generally shown reduced bond strength of resin cement to zirconia after different artificial thermocycling periods. Compared to water storage at constant temperature only, thermocycling has a greater impact on the bond durability between the zirconia and resin cements [31,32]. Kern and Wegner [31] evaluated the bond strength to zirconia after 150 days of water storage only or water storage followed by thermocycling [32]. In another study, significant reduction in adhesion was reported after artificial aging for 180 days combined with thermocycling $\left(12.000\right.$ cycles, $\left.5^{\circ} \mathrm{C}-60^{\circ} \mathrm{C}\right)$ [33]. The authors concluded that air-abrasion combined with the use of an MDP-based cement resulted in more durable adhesion, demonstrating only cohesive failures in the cement. In the present study, specimens of all groups subjected to thermocycling, showed spontaneous debondings. Thus, the thermocycling factor could not be analyzed. On the other hand, the specimens tested without aging conditions, presented mainly cohesive failure of the cement or mixed failure type. These types of failures indicate some degree of adhesion that does not surpass the cohesive strength of zirconia. Exclusively adhesive failures observed in the control group imply the necessity of physico-chemical surface conditioning of zirconia.

In previous study, no adhesion was obtained after air-abrasion with alumina and silanization following thermocycling [15]. This poor adhesion was attributed to the hydrolysis of Al-O-Si in aqueous conditions $[34,35]$. The results of this study contradict with what was found by Amaral et al. [20], who reported stable adhesion to zirconia even after 
thermocycling when the surface was coated by silica. It has to be noted that in that study, microtensile test was used. It is most probable that the aging effect of thermocycling in the resin-zirconia interface in the bonded specimens are less than those prepared for shear test. This aspect warrants further investigation.

Clinical success of bonded FDPs relies on the adhesion of the resin cement to both the restoration and the dental tissues. Thus, further in vitro and in vivo studies should be developed with the aim of clarifying the influence of surface conditioning methods on the adhesion of resin cements to both zirconia and tooth substrates.

\section{Conclusions}

From this study, the following could be concluded:

1. Air-abrasion with $110 \mu \mathrm{m}$ alumina or $110 \mu \mathrm{m}$ alumina particles coated with silica increased surface roughness and shear bond strength of the MDP containing resin cement to zirconia compared to the control group.

2. The use of alumina particles coated with silica revealed less damage on zirconia and showed increased bond strength compared to air-abrasion with alumina.

3. Increasing blasting pressure from 2.5 to 3.5 bar increased the surface roughness values but it did not affect the mean bond strength of the resin cement to zirconia.

4. After 6000 thermocycling, spontaneous debondings in all groups indicates that adhesion to zirconia is prone to aging. 


\section{References}

[1] Sundh A, Molin M, Sjögren G. Fracture resistance of yttrium oxide partiallystabilized zirconia all-ceramic bridges after veneering and mechanical fatigue testing. Dent Mater 2005;21:476-82.

[2] Xible AA, de Jesus Tavarez RR, de Araujo CoR, Bonachela WC. Effect of silica coating and silanization on flexural and composite-resin bond strengths of zirconia posts: An in vitro study. J Prosthet Dent 2006;95:224-9.

[3] Piconi C, Maccauro G. Zirconia as a ceramic biomaterial. Biomaterials 1999;20 (1):1-25.

[4] Raigrodski AJ, Hillstead MB, Meng GK, Chung KH. Survival and complications of zirconia-based fixed dental prostheses: a systematic review. J Prosthet Dent 2012;107:170-7. 
[5] Ohlmann B, Rammelsberg P, Schmitter M, Schwarz S, Gabbert O. All-ceramic inlay-retained fixed partial dentures: preliminary results from a clinical study. J Dent 2008;36:692-6.

[6] Molin MK, Karlsson SL. Five-year clinical prospective evaluation of zirconia-based Denzir 3-unit FPDs. Int J Prosthodont 2008;21:223-7.

[7] Özcan M, Vallittu PK. Effect of surface conditioning methods on the bond strength of luting cement to ceramics. Dent Mater 2003;19:725-31.

[8] Silva NR, Coelho PG, Valverde GB, Becker K, Ihrke R, Quade A, et al. Surface characterization of $\mathrm{Ti}$ and $\mathrm{Y}$-TZP following non-thermal plasma exposure. J Biomed Mater Res B Appl Biomater 2011;99:199-206.

[9] Aboushelib MN, Kleverlaan CJ, Feilzer AJ. Selective infiltration-etching technique for a strong and durable bond of resin cements to zirconia-based materials. J Prosthet Dent 2007;98:379-88.

[10] May L, Passos S, Capelli D, Özcan M, Bottino M, Valandro L. Effect of silica coating combined to a MDP-based primer on the resin bond to Y-TZP ceramic. J Biomed Mater Res B Appl Biomater 2010;95:69-74.

[11] Ntala P, Chen X, Niggli J, Cattell M. Development and testing of multi-phase glazes for adhesive bonding to zirconia substrates. J Dent 2010;38:773-81.

[12] Amaral R, Özcan M, Bottino MA, Valandro LF. Microtensile bond strength of a resin cement to glass infiltrated zirconia-reinforced ceramic: the effect of surface conditioning. Dent Mater 2006;22:283-90.

[13] Wolfart M, Lehmann F, Wolfart S, Kern M. Durability of the resin bond strength to zirconia ceramic after using different surface conditioning methods. Dent Mater $2007 ; 23: 45-50$. 
[14] Akgungor G, Sen D, Aydin M. Influence of different surface treatments on the shortterm bond strength and durability between a zirconia post and a composite resin core material. J Prosthet Dent 2008;99:388-99.

[15] Yang B, Barloi A, Kern M. Influence of air-abrasion on zirconia ceramic bonding using an adhesive composite resin. Dent Mater 2010;26:44-50.

[16] Yun J, Ha S, Lee J, Kim S. Effect of sandblasting and various metal primers on the shear bond strength of resin cement to Y-TZP ceramic. Dent Mater 2010;26:650-8.

[17] Oyagüe RC, Monticelli F, Toledano M, Osorio E, Ferrari M, Osorio R. Effect of water aging on microtensile bond strength of dual-cured resin cements to pre-treated sintered zirconium-oxide ceramics. Dent Mater 2009;25:392-9.

[18] Sato H, Yamada K, Pezzotti G, Nawa M, Ban S. Mechanical properties of dental zirconia ceramics changed with sandblasting and heat treatment. Dent Mater $\mathrm{J}$ 2008;27:408-14.

[19] Spohr AM, Sobrinho LC, Consani S, Sinhoreti MA, Knowles JC. Influence of surface conditions and silane agent on the bond of resin to IPS Empress 2 ceramic. Int $\mathrm{J}$ Prosthodont 2003;16:277-82.

[20] Amaral R, Özcan M, Valandro LF, Balducci I, Bottino MA. Effect of conditioning methods on the microtensile bond strength of phosphate monomer-based cement on zirconia ceramic in dry and aged conditions. J Biomed Mater Res B Appl Biomater 2008;85:1-9.

[21] Karakoca S, Yilmaz H. Influence of surface treatments on surface roughness, phase transformation, and biaxial flexural strength of $\mathrm{Y}$-TZP ceramics. J Biomed Mater Res B Appl Biomater 2009;91:930-7.

[22] International Standardization Organization (ISO). TR ISO 10477: 2000. Polymerbased crown and bridge materials. Berlin; 2000. 
[23] Özcan M, Melo R, Souza R, Valandro LF, Machado JP, Bottino M. Effect of air-particle abrasion protocols on the biaxial flexural strength, surface characteristics and phase transformation of zirconia after cyclic loading. J Mech Behav Biomed Mater 10: 227-34.

[24] de Oyagüe R, Monticelli F, Toledano M, Osorio E, Ferrari M, Osorio R. Influence of surface treatments and resin cement selection on bonding to densely-sintered zirconiumoxide ceramic. Dent Mater 2009;25:172-9.

[25] Cattani Lorente M, Scherrer S, Richard J, Demellayer R, Amez-Droz M, Wiskott H. Surface roughness and EDS characterization of a Y-TZP dental ceramic treated with the CoJet $^{\text {TM }}$ Sand. Dent Mater 2010;26:1035-42.

[26] Qeblawi D, Muñoz C, Brewer J, Monaco EJ. The effect of zirconia surface treatment on flexural strength and shear bond strength to a resin cement. $\mathrm{J}$ Prosthet Dent 2010;103:210-20.

[27] Kern M. Resin bonding to oxide ceramics for dental restorations. J Adhes Sci Technol 2009;23:1097-111.

[28] Özcan M, Cura C, Valandro LF. Early bond strength of two resin cements to Y-TZP ceramic using MPS or MPS/4-META silanes. Odontology 2011;99:62-7.

[29] Gale M, Darvell B. Thermal cycling procedures for laboratory testing of dental restorations. J Dent 1999;27:89-99.

[30] International Standardization Organization (ISO). ISO TR 11405:1994. Dental materials- Guidance on testing of adhesion to tooth structure. Geneva; 1994.

[31] Kern M, Wegner S. Bonding to zirconia ceramic: adhesion methods and their durability. Dent Mater 1998;14:64-71.

[32] Wegner S, Kern M. Long-term resin bond strength to zirconia ceramic. J Adhes Dent 2000;2:139-47. 
[33] Michida S, Valandro L, Yoshiga S, Andreatta Filho O, Balducci I, Bottino MA. Effect of surface treatment of a glass-infiltrated alumina ceramic on the microtensile bond strength. J Appl Oral Sci 2003;11:361-6.

[34] Blatz M, Sadan A, Martin J, Lang B. In vitro evaluation of shear bond strengths of resin to densely-sintered high-purity zirconium-oxide ceramic after long-term storage and thermal cycling. J Prosthet Dent 2004;91:356-62.

[35] Valandro L, Özcan M, Bottino M, Bottino M, Scotti R, Bona A. Bond strength of a resin cement to high-alumina and zirconia-reinforced ceramics: the effect of surface conditioning. J Adhes Dent 2006;8:175-81. 


\section{Captions to the tables and figures:}

\section{Tables}

Table I. Brands, types, manufacturers and batch numbers of the materials used in this study.

Table II. Experimental groups and group abbreviations for surface roughness test according to the main factors: particle type ( 2 levels) and pressure ( 2 levels). ${ }^{*} n=3$ per group

Table III. Experimental groups for shear bond strength test according to the main factors: particle type ( 2 levels), pressure ( 2 levels) and thermocycling (2 levels). ${ }^{*} n=10$ per group Table IV. Results of two-way analysis of variance (ANOVA) and the interaction terms for surface roughness $(\mathrm{Ra})$ measurements depending on particle type and pressure $\left({ }^{*} p<\right.$ 0.05).

Table V. Results of two-way analysis of variance (ANOVA) and the interaction terms for shear bond strength (MPa) depending on particle type and pressure $\left({ }^{*} p<0.05\right)$.

Table VI. Number (N) of specimens produced, percentage (\%) of pre-test failures (PTF) during thermal cycling (TC) or water storage and number of tested specimens (TE).

Table VII. Incidence of failure types (\%) for the experimental groups: Score a: adhesive failure between the ceramic-cement; Score b: cohesive failure in the ceramic; Score c: cohesive failure in the cement and Score $\mathrm{d}$ : mixed failure (adhesive failure together with cohesive failure in the cement).

\section{Figures}


Figure 1. Means and standard deviations of the roughness surface values $(\mathrm{Ra})$ according to the experimental conditions. Control group ${ }^{\mathrm{C}}, \mathrm{Al} 2.5^{\mathrm{C}}, \mathrm{Si} 2.5^{\mathrm{D}}, \mathrm{Al} 3.5^{\mathrm{A}}, \mathrm{Si} 3.5^{\mathrm{B}}$ (Dunnet test, $p<0.05)$. For group abbreviation see Table II.

Figure 2a-f. a) Scanning Electron Microscopy (SEM) photomicrograph (x5000) and b) 3D graphic representation of the surface topography of the non-abraded control zirconia; c) SEM photomicrograph $(x 5000)$ and d) 3D graphic representation of the surface topography of zirconia air-abraded with Al3.5; e) SEM (x5000) and f) 3D graphic representation of the surface topography of zirconia air-abraded with Si3.5. Note the more aggressive topography change after air-abrasion with Al3.5 compared to control and Si3.5. Figure 3. Means and standard deviations of the shear bond strength for the experimental groups. Control group ${ }^{\mathrm{B}}, \mathrm{Al} 2.5^{\mathrm{B}}, \mathrm{Si} 2.5^{\mathrm{A}}, \mathrm{Al} 3.5^{\mathrm{B}}, \mathrm{Si} 3.5^{\mathrm{A}}$ (Tukey`s, $p<0.05$ ). For group abbreviation see Table II. 


\section{Tables}

Table I. Brands, types, manufacturers and batch numbers of the materials used in this study.

\begin{tabular}{|c|c|c|c|}
\hline Brand & Type & Manufacturer & Batch num \\
\hline Lava & Y-TZP ceramic block & $\begin{array}{l}\text { 3M ESPE, Seefeld, } \\
\text { Germany }\end{array}$ & 391266 \\
\hline $\begin{array}{l}\text { Aluminum } \\
\text { oxide }\end{array}$ & Aluminum oxide $(110 \mu \mathrm{m})$ & $\begin{array}{l}\text { Polidental Ltd., São } \\
\text { Paulo, Brazil }\end{array}$ & 21567 \\
\hline Rocatec Plus & $\begin{array}{l}\text { Aluminum oxide coated with silica } \\
\qquad(110 \mu \mathrm{m})\end{array}$ & 3M ESPE & 269078 \\
\hline $\begin{array}{l}\text { ClearFill } \\
\text { Ceramic } \\
\text { Primer }\end{array}$ & $\begin{array}{c}\text { MDP, HEMA, hydrophilic } \\
\text { dimethacrylates, } \\
\text { dl-camphorquinone, } \\
\text { N,N-diethanol-p-toluidine, } \\
\mathrm{H}_{2} \mathrm{O}\end{array}$ & $\begin{array}{c}\text { Kuraray Co. Ltd, Osaka, } \\
\text { Japan }\end{array}$ & 00009C \\
\hline Panavia F2.0 & $\begin{array}{l}\text { Paste A: silica, dimethacrylate } \\
\text { monomer, functional acid MDP, } \\
\text { photo-initiator, accelerator; } \\
\text { Paste B: brown color, barium } \\
\text { glass, sodium fluoride, } \\
\text { dimethacrylate } \\
\text { (DMA) monomer }\end{array}$ & Kuraray Co. Ltd. & $\begin{array}{l}\text { 340AA } \\
\text { 062BA }\end{array}$ \\
\hline
\end{tabular}


Table II. Experimental groups and group abbreviations for surface roughness test according to the main factors: particle type ( 2 levels) and pressure ( 2 levels). ${ }^{*} n=3$ per group

\begin{tabular}{ccc}
\hline & \multicolumn{2}{c}{ Air-particle-abrasion } \\
Group Abbreviations & Particle type & Pressure (bar) \\
\hline Control & - & - \\
Al2.5 & $\mathrm{Al}_{2} \mathrm{O}_{3}$ & 2.5 \\
Si2.5 & $\mathrm{SiO}_{2}$ & 2.5 \\
Al3.5 & $\mathrm{Al}_{2} \mathrm{O}_{3}$ & 3.5 \\
$\mathrm{Si} 3.5$ & $\mathrm{SiO}_{2}$ & 2.5 \\
\hline
\end{tabular}

Table III. Experimental groups for shear bond strength test according to the main factors: particle type (2 levels), pressure ( 2 levels) and thermocycling (2 levels). * $n=10$ per group

\begin{tabular}{cccc} 
Groups & Particle type & Pressure (bar) & Thermocycling \\
\hline Control & - & - & Without \\
Al2.5 & $\mathrm{Al}_{2} \mathrm{O}_{3}$ & 2.5 & Without \\
Si2.5 & $\mathrm{SiO}_{2}$ & 2.5 & Without \\
Al3.5 & $\mathrm{Al}_{2} \mathrm{O}_{3}$ & 3.5 & Without \\
Si3.5 & $\mathrm{SiO}_{2}$ & 3.5 & Without \\
Control & - & - & With
\end{tabular}




\begin{tabular}{llll}
$\mathrm{Al} 2.5_{\mathrm{TC}}$ & $\mathrm{Al}_{2} \mathrm{O}_{3}$ & 2.5 & With \\
$\mathrm{Si} 2.5_{\mathrm{TC}}$ & $\mathrm{SiO}_{2}$ & 2.5 & With \\
$\mathrm{Al} 3.5_{\mathrm{TC}}$ & $\mathrm{Al}_{2} \mathrm{O}_{3}$ & 3.5 & With \\
$\mathrm{Si} 3.5_{\mathrm{TC}}$ & $\mathrm{SiO}_{2}$ & 3.5 & With \\
\hline
\end{tabular}

Table IV. Results of two-way analysis of variance (ANOVA) and the interaction terms for surface roughness $(\mathrm{Ra})$ measurements depending on particle type and pressure $\left({ }^{*} p<0.05\right)$.

\begin{tabular}{cccccc}
\hline Effect & DF & SS & MS & F & $P$ \\
& & & & & \\
\hline Particle type & 1 & 0.03521 & 0.03521 & 352.08 & $0.0001^{*}$ \\
Pressure & 1 & 0.26701 & 0.26701 & 2670.08 & $0.0001^{*}$ \\
& & & & & \\
Particle type x Pressure & 1 & 0.00801 & 0.00801 & 80.08 & $0.0001^{*}$ \\
Error & 8 & 0.00080 & 0.00010 & & \\
Total & 11 & 0.31103 & & & \\
& & & & & \\
\hline
\end{tabular}


Table V. Results of two-way analysis of variance (ANOVA) and the interaction terms for shear bond strength $(\mathrm{MPa})$ depending on particle type and pressure $\left({ }^{*} p<0.05\right)$.

\begin{tabular}{cccccc}
\hline Effect & DF & SQ & QM & F & $p$ \\
\hline Particle type & 1 & 72055 & 720553 & 6.86 & $0.0150^{*}$ \\
Pressure & 1 & 7781 & 77806 & 0.74 & 0.3980 \\
& & & & & \\
Particle type x Pressure & 1 & 5296 & 52955 & 0.50 & 0.4846 \\
Error & & & & & \\
Total & 24 & 252142 & 105059 & & \\
& & & & &
\end{tabular}

Table VI. Number (N) of specimens produced, percentage (\%) of pre-test failures (PTF) during thermal cycling (TC) or water storage and number of tested specimens (TE). 


\begin{tabular}{cccc} 
Groups & $\mathbf{N}$ & $\mathbf{N}(\%)$ of PTF & $\mathbf{N}(\%)$ TE \\
\hline Control & 10 & 0 & $10(100)$ \\
Al2.5 & 10 & 0 & $10(100)$ \\
Si2.5 & 10 & 0 & $10(100)$ \\
Al3.5 & 10 & 0 & $10(100)$ \\
Si3.5 & 10 & 0 & $10(100)$ \\
C $_{\text {TC }}$ & 10 & $10(100)$ & 0 \\
Al2.5 & 10 & $10(100)$ & 0 \\
Si2.5 & 10 & $10(100)$ & 0 \\
Al3.5 5 TC & 10 & $10(100)$ & 0 \\
Si3.5 5 TC & 10 & $10(100)$ & 0 \\
\hline
\end{tabular}

Table VII. Incidence of failure types (\%) for the experimental groups: Score a: adhesive failure between the ceramic-cement; Score b: cohesive failure in the ceramic; Score c: cohesive failure in the cement and Score $\mathrm{d}$ : mixed failure (adhesive failure together with cohesive failure in the cement).

\begin{tabular}{|c|c|c|c|c|}
\hline \multirow{2}{*}{ Groups } & \multicolumn{5}{|c|}{ Failure types } \\
\hline Control & A & B & C & D \\
\hline Al2.5 & - & - & - & 100 \\
\hline Si2.5 & - & - & 20 & 80 \\
\hline Al3.5 & - & - & 10 & 90 \\
\hline Si3.5 & - & - & 10 & 90 \\
\hline Control & - & - & 20 & 80 \\
\hline Al2 & 100 & - & - & - \\
\hline Si2.5TC & 100 & - & - & - \\
\hline Al3.5TC & 100 & - & - & - \\
\hline Si3.5TC & 100 & - & - & - \\
\hline
\end{tabular}

Figures 
Surface Roughness (Ra, $\mu \mathrm{m})$

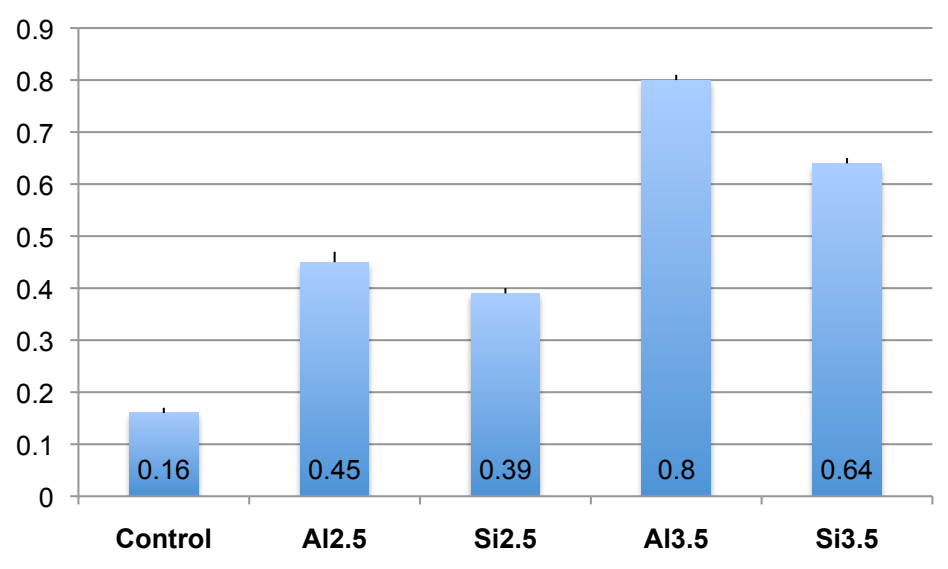

Figure 1. Means and standard deviations of the roughness surface values $(\mathrm{Ra})$ according to the experimental conditions. Control group ${ }^{\mathrm{C}}, \mathrm{Al} 2.5^{\mathrm{C}}, \mathrm{Si}^{2} .5^{\mathrm{D}}, \mathrm{Al} 3.5^{\mathrm{A}}, \mathrm{Si}^{3} 5^{\mathrm{B}}$ (Dunnet test, $p<0.05$ ). For group abbreviation see Table II. 


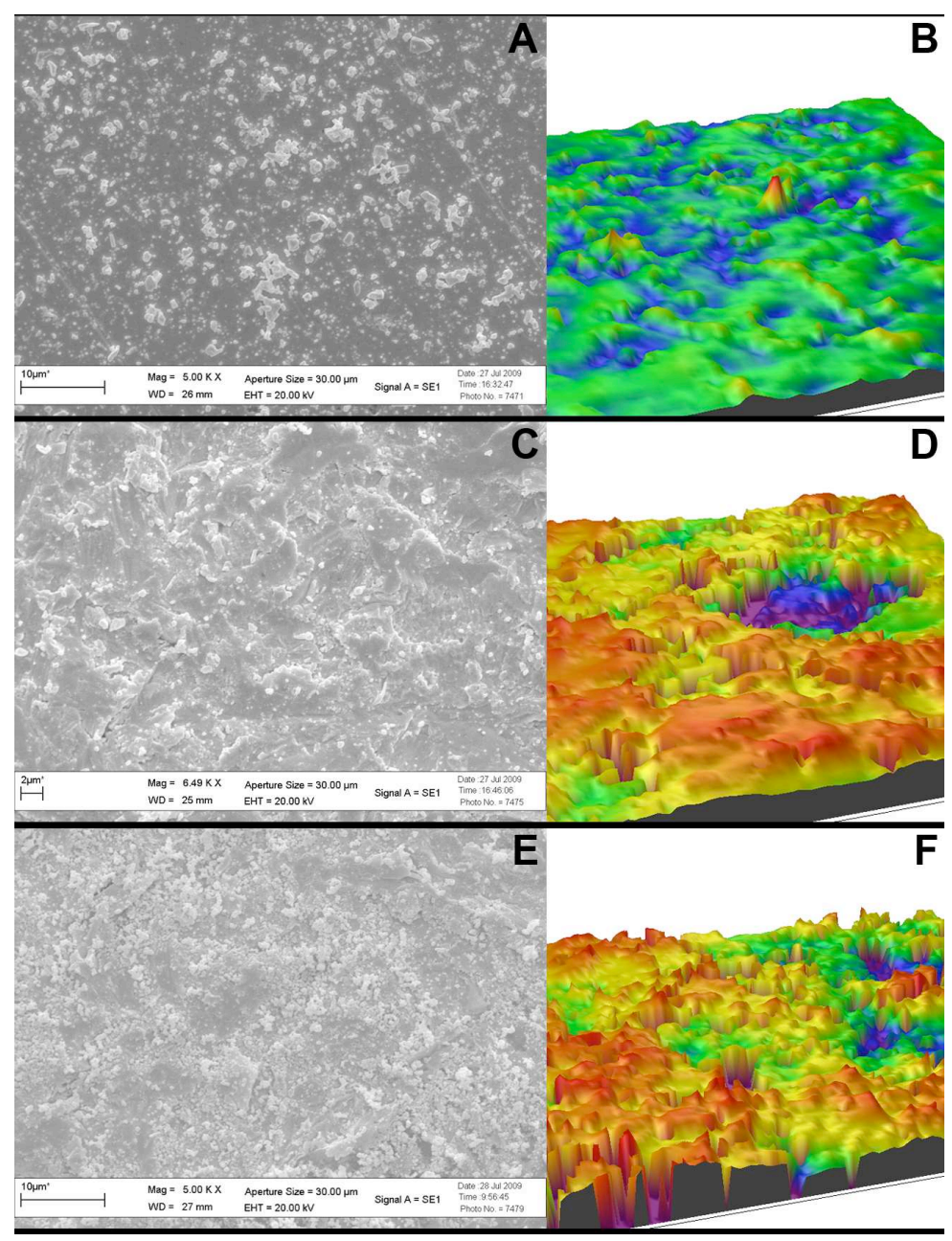

Figure 2a-f. a) Scanning Electron Microscopy (SEM) photomicrograph (x5000) and b) 3D graphic representation of the surface topography of the non-abraded control zirconia; c) SEM photomicrograph (x5000) and d) 3D graphic representation of the surface topography of zirconia air-abraded with Al3.5; e) SEM (x5000) and f) 3D graphic representation of the surface topography of zirconia air-abraded with Si3.5. Note the more aggressive topography change after air-abrasion with Al3.5 compared to control and Si3.5. 


\section{Shear Bond Strength (MPa)}

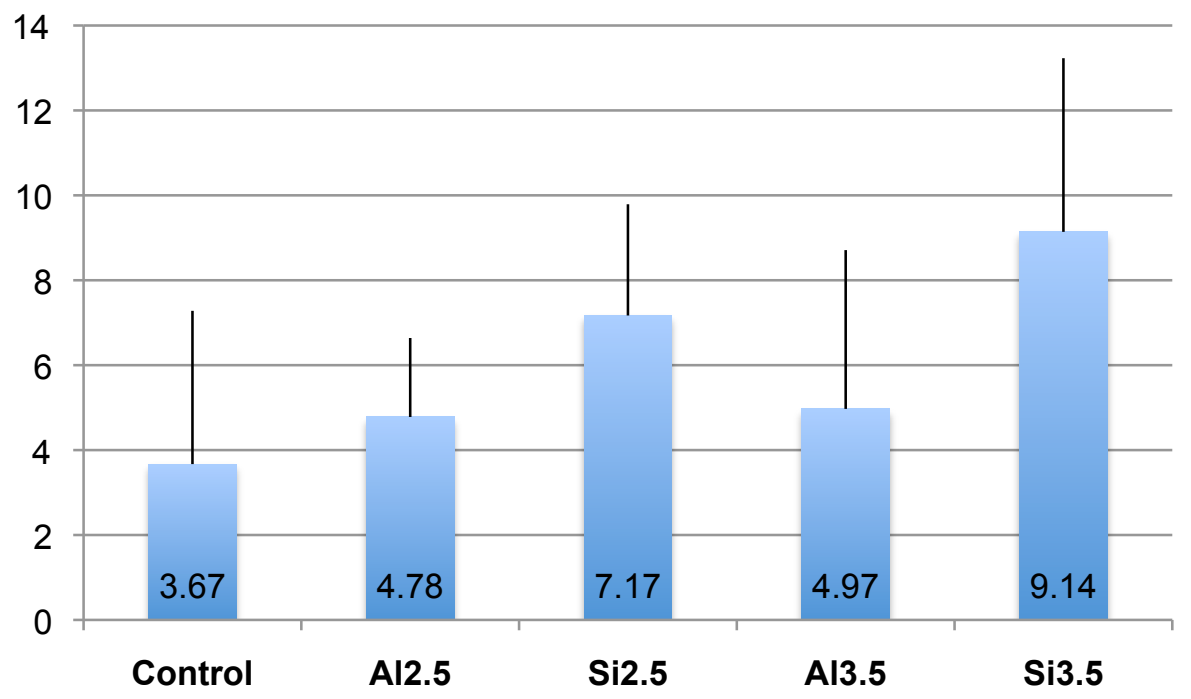

Figure 3. Means and standard deviations of the shear bond strength for the experimental groups. Control group ${ }^{\mathrm{B}}, \mathrm{Al} 2.5^{\mathrm{B}}, \mathrm{Si} 2.5^{\mathrm{A}}, \mathrm{Al} 3.5^{\mathrm{B}}, \mathrm{Si} 3.5^{\mathrm{A}}$ (Tukey`s, $p<0.05$ ). For group abbreviation see Table II. 